\title{
THE MONSTER OF TROY VASE IS NOT BASED ON A FOSSIL GIRAFFE
}

\author{
(Short title: MONSTER OF TROY VASE IS NOT A GIRAFFE)
}

Summary. It has been proposed that the Monster of Troy, depicted in a 6th Century BC Corinthian vase, is the earliest artistic record of a vertebrate fossil, possibly a Miocene giraffe (Samotherium sp.). I analyzed the giraffe hypothesis under four approaches: a double-blind random design in which 78 biologists compared the vase skull with Samotherium and several reptiles; an informed survey of 30 students who critically assessed the hypothesis; a computerized image comparison; and a morphological comparison. All of them rejected the giraffe hypothesis. Eye and teeth types unambiguously discard a fossil or living mammal as the model, which more probably was an extant carnivorous reptile.

\section{INTRODUCTION}

In volume 19 of the Oxford Journal of Archaeology, it was proposed that the Monster of Troy, depicted in a 6th Century BC Corinthian vase, was not purely imaginary, as previously believed, but the earliest artistic record of a vertebrate fossil, possibly a Miocene giraffe, Samotherium, with details from other animals, like insect antennae, added for effect (Mayor 2000, 157-162; 2011, Figs. 4.1-4.3). Despite the nearly two decades elapsed since publication, no formal scientific articles have analyzed this idea, but paleontologists have rejected them online, including Protoceratops and Dracorex as inspiration for griffins and dragons, because they do not match chronologically, geographically and morphologically (Bosscher 2014; Witton 2016). Another suggestion of large fossils was also rejected, based on contemporaneous texts that clearly associated the bones with extant whales (Papadopoulos \& Ruscillo 2002, 210).

Here, I test both the mammal-giraffe hypothesis of Mayor $(2000,57)$ and the hypotheses of Bosscher (2014) who proposed that the model could have been a plesiosaur, a mosasaur, or, more probably, some species of monitor lizard.

\section{METHODS}

Double blind experiment: software was used to present, online, several images to 78 volunteer professional biologists who were asked which skull more closely resembled the skull in the vase 
(google.com/forms). To prevent bias, they ignored the nature of the study, and all skulls were redrawn as standardized anatomical outlines and presented to them in random order. The assistant who tabulated the results was also unaware of the nature of the study.

Informed experiment: 30 college students from varied fields were explained the hypotheses and given un-retouched photographic images of a variety of similar skulls and the vase (all kindly provided by Dr. A. Mayor).

Automatic analysis: anatomical outlines of the skull, all in the same style and size, were compared for species that could have been known to the artist (considering time and place) with the software IMG (IMGonline.com.ua).

Morphological analysis: eye type and dentition type were compared in photographs of the vase, the fossil giraffe and extant reptiles (Figure 1).

All survey forms, images and raw data are available from the author upon request.

\section{RESULTS}

In the online test, 58 biologists associated the drawing of the vase skull with the lizard Varanus exanthematicus, ten with Plesiosaurus dolichodeirus, eight with the mosasaur Prognathodon stadtmani and only two with the fossil giraffe Samotherium boissieri; the preference was highly significant (Chi-Square Test=103; Prob. <0.0001).

The informed students mostly associated the vase skull with Oxydactylus (an extinct North American camel that could not have been seen by the vase artist, $\mathrm{N}=15$ ), followed by Pakicetus (extinct cetacean from Pakistan, N=5), and two students each with crocodiles, horses, the Samotherium giraffe, the lizard Varanus exanthematicus and the lizard Varanus griseus (both from Africa).

Software assigned the highest similarity score to Plesiosaurus (6.55\%), followed by Varanus niloticus $(6.53 \%)$ and the Samotherium giraffe (5.06\%).

Including an sclerotic ring in the eye and sharp teeth (Figure 1a), the eye type and dentition represented on the vase are typical of reptilian predators (Figure 1b); while mammals lack sclerotic rings and, in the case of giraffes, have grinding molars that are completely different from the jaws in the vase (Figure 1c). 


\section{DISCUSSION}

The fact that a foreign species -that could not be known to the vase artist- was selected by the informed students, is in itself interesting and emphasizes the value of less subjective approaches used here, such as automatic computer analysis and morphological comparison.

In any case, the four tests rejected the fossil mammal/giraffe hypothesis. The eye with sclerotic ring and the teeth shape unambiguously discard a fossil or living mammal -giraffe or other- as the model (Hall-Martin 1976, 286; Atkins 2014, 65).

Mora probably, the model was a carnivorous reptile, like the extant giant lizards of the genus Varanus, which have a characteristic skull, eye and teeth shape (Delfino et al. 2011, 97-98) that match the vase monster. The interpretation of the dark area as a rock and the shorter upper jaw as a broken bone is not the only possible interpretation, it can also represent a dark cave, the monster's body, or simply result from the poor skill of the artist, as shown by the wrong proportions of the Heracles arms, Hesione's misshapen face and wrongly proportioned horses in the same vase.

Paraphrasing what Witton (2016) wrote about the griffin hypothesis, even though the eroded fossil suggestion is attractive, everything in the image can be "best and entirely explained" as the representation of a skull of a living species of reptile, and "there is no need to invoke any exotic fossil anatomies".

Dr. Mayor's contribution in reviving interest in the subject must be fully recognized and appreciated. I hope her work will inspire further studies about other possible fossil influences on cultural expressions, just like it inspired this note.

\section{Acknowledgements}

I thank Dr. Adrianne Mayor for constructive criticism and for the images used to redo this study after she identified methodological errors in an earlier attempt; and Karina Barrientos, Sergio Quesada, Carolina Seas and Melania Vargas for assistance with the surveys. 


\section{REFERENCES}

ATKINS, J. 2014: The sclerotic ring: evolutionary trends in squamates. M.Sc. Thesis, Saint Mary's University, Halifax, Nova Scotia.

BOSSCHER, M. 2014. Mythical monsters and ancient fossils.

http://hospitem.blogspot.com/2014/07 [Accesed 09 Aug 2018]

DELFINO, M., ALBA, D., CARMONA, R., LUJAN, A. and ROBLES, J. 2011: European monitor lizards (Anguimorpha, Varanidae, Varanus): new materials and new perspectives. Journal of Vertebrate Paleontology 31, 97-98.

HALL-MARTIN, A.J. 1976: Dentition and age determination of the giraffe Giraffa camelopardalis. Journal of Zoology 180(2), 263-289.

MAYOR, A. 2000: The 'Monster of Troy' Vase: The Earliest Artistic Record of a Vertebrate Fossil Discovery? Oxford Journal of Archaeology 19(1), 57-63.

MAYOR, A. 2011: The First Fossil Hunters: Dinosaurs, Mammoths, and Myth in Greek and Roman Times (Princeton)

PAPADOPOULOS, J. K. and RUSCILLO, D. 2002: A Ketos in early Athens: an archaeology of whales and sea monsters in the Greek World. American Journal of Archaeology 106(2), 187-227.

WITTON, M. 2016: Why Protoceratops almost certainly wasn't the inspiration for the griffin legend. https://markwitton-com.blogspot.com/2016/04/why-protoceratops-almost-certainly.html [Accesed 09 Aug 2018]

\section{Captions of Illustration}

Figure 1. A. Monitor lizard. B. Troy Monster. C. Samotherium giraffe. D. Detail of modern giraffe teeth. Credits: R. Hill, reptileforums; B. J. Glazier, Flikr, C\&D wikimedia (Ghedoghedo). https://www.reptileforums.co.uk/forums/lizards/207665-monitors-tegus-229.html https://www.flickr.com/photos/jag_jaf_travel/26507204280/ 


\section{JULIÁN MONGE-NÁJERA}

Laboratorio de Ecología Urbana, Vicerrectoría de Investigación, Universidad Estatal a Distancia, 2050 San José, Costa Rica; jmonge@uned.ac.cr and julianmonge@gmail.com 